\title{
Afirmar e querer negar: os limites da negação da vontade na obra madura de Schopenhauer
}

\author{
Affirm and want to deny: the limits of the negation of will in \\ Schopenhauer's mature work
}

\author{
Eduardo Ribeiro da Fonseca \\ Professor do Departamento de Filosofia e do Programa de Pós-Gradução em Filosofia da Pontifícia \\ Universidade Católica do Paraná (PUCPR). \\ Membro da Seção Brasileira da Schopenhauer-Gesellschaft. \\ E-mail: eduardorfonseca@uol.com.br
}

Resumo: 0 presente artigo procura opor a característica eminentemente afirmativa da Vontade à possibilidade da autonegação, ou, dito de outro modo, expor a contradição do fenômeno consigo mesmo. Desse dilaceramento íntimo, do intenso sofrimento pessoal, bem como do consequente elevar-se acima de sua individualidade, resultaria o repúdio de si mesmo. Do mesmo modo que mesmo no repúdio sempre se trata da atividade da vontade, também a supressão do querer presente na contemplação estética é analisada a partir da noção de que a vontade desaparece apenas da consciência, e não da contemplação em si mesma. Nesse sentido, os alvos, mesmo não sendo os da consciência comum, ainda são alvos sublimados da vontade.

Palavras-chave: Vontade; Consciência Afirmação; Negação.
Abstract: This article seeks to oppose the eminently affirmative characteristic of the Will to the possibility of self-denial, or the contradiction of the phenomenon with itself. From this intimate laceration, from the intense personal suffering, as well as from the consequent elevation above its individuality, would result the repudiation of itself. In the same way that we are always talking about the activity of the will, even in negation, also the suppression of the Will present in the aesthetic contemplation is analyzed considering the notion that the will disappears only from the consciousness, and not from contemplation itself. In this sense, the targets, even though they are not those present in the common consciousness, are still sublimated targets of the Will.

Keywords: Will; Consciousness; Affirmation; Denial. 


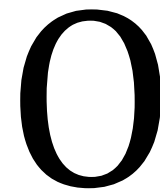

que será abordado neste escrito é, primeiramente, a insistência com que Schopenhauer escreve sobre a característica eminentemente afirmativa da Vontade em contraste com a possibilidade da autonegação (Selbstverneinung), dito de outro modo, a "contradição do fenômeno consigo mesmo"1, que se baseia no intenso sofrimento pessoal, bem como o consequente elevar-se acima de sua individualidade, de que decorre o repúdio de si mesmo (Selbstverleugnung) ${ }^{2}$. Ao pensarmos a afirmação da vontade nos deparamos com a suspensão provisória ou permanente do querer, isto é, no contexto da teoria schopenhaueriana do belo e da contemplação das ideias platônicas e também no contexto de sua assim chamada grande ética, isto é, do ponto de vista da significação moral do mundo e dos dois modos, afirmativo e negativo, através dos quais a vontade se manifesta e experimenta a avaliação de sua condição dilacerada no âmbito da individuação. Essa autopercepção da vontade pode resultar em duas atitudes básicas. Uma positiva ou afirmativa, em caso de aprovação incondicional da vida, e uma atitude negativa, caso fique decepcionada com o que ela mesma é ao se mirar no espelho da representação. Esta segunda atitude implicaria numa alteração significativa e radical do querer, do wollen, ou pode ser compreendida também, no contexto da metafísica imanente, como uma afirmação da negação, uma satisfação substitutiva, sintomática, como um gozo através do próprio sofrimento? $\mathrm{Ou}$, num outro sentido, como um predomínio quase antinatural dos impulsos inerentes ao próprio cérebro? Existiriam elementos na filosofia de Schopenhauer e até mesmo na Metafísica do Belo, que nos conduzam, talvez, a este resultado?

Além do que mencionei acima, tenho também a intenção de mencionar e comentar trechos do texto de Schopenhauer traduzido por mim, intitulado Sobre a liberdade da vontade, do ponto de vista das possibilidades e limites de afirmação do querer-viver (e aí entram as questões relacionadas ao organismo e à liberdade da vontade), com o objetivo de questionar em que medida seria de fato possível negar (partindo do que é dito ali), ainda que provisoriamente, o querer inconsciente. Isso nos conduz à questão ética mencionada por Schopenhauer naquele texto: "Eu posso fazer o

\footnotetext{
${ }^{1}$ SCHOPENHAUER, A. WWV I, § 68, p. 464. Nesse ponto da obra Schopenhauer explica, por assim dizer, o processo psíquico da autonegação e percebemos a veemência da vontade negando a si mesma, o que não deixa de ser curioso e (por que não?) um tanto paradoxal.

2 Ibidem, § 55, p. 339. No trecho em questão, Schopenhauer utiliza os dois termos: Selbstveneinung e Selbstverleugnung. 
que eu quero?" Dizendo de outro modo, o que significa dizer naquele escrito que "eu posso fazer o que eu quero"? E, explorando as consequências da perspectiva afirmativa da obra do filósofo de Danzig, teríamos necessariamente que questionar também o seguinte: se o intelecto não pode saber tudo, como escreve Schopenhauer em diversos lugares, talvez precisássemos admitir (ao menos de acordo com uma das perspectivas presentes na obra) que a negativa, seja como Verneinung, como Verwerfung ou Verleugnung, possa ser em si mesma um excelente disfarce para as formas sublimatórias ou sintomáticas de um querer inconsciente. A captação da consciência pela vontade inconsciente é um dos temas mais ricos dos Ergänzungen de 1844 (especialmente no capítulo XIX) ${ }^{3}$, por exemplo, e o mesmo ocorre em Sobre a vontade na natureza ${ }^{4}$ e, como mencionei, também em Sobre a liberdade da vontade ${ }^{5}$. Para o filósofo seria mesmo qualquer coisa de antinatural ou sobrenatural se a vontade não se afirmasse em cada pequena coisa, em cada traço de caráter, em cada desejo, em toda e qualquer ação consciente, inconsciente ou mesmo involuntária (por exemplo, no caso do sistema nervoso autônomo). E isso nos conduz ao problema da possibilidade efetiva da negativa como um oposto da afirmação.

\section{Entre afirmar, silenciar e negar}

As possibilidades de silenciar momentaneamente (na contemplação estética) ou de negar a vontade, no contexto da Ética, não aparecem diante de nós como hipóteses tão confiáveis frente à armadilha representada pela veemência com que Schopenhauer exalta essa mesma Vontade como o fulcro de toda coisa existente, e que em si mesma ela seria incomensurável com a representação, aceitando apenas definições negativas. Esse é o preço pago pela imanência. Para Schopenhauer, do ponto de vista do silêncio da vontade na contemplação há um fator específico, que são os Triebe (impulsos) do próprio cérebro, como ele diz ao final do capítulo dos Ergänzungen chamado "Sobre o puro sujeito do conhecimento", já que o cérebro é igualmente uma estrutura orgânica e,

\footnotetext{
3 SCHOPENHAUER, A. WWV II/ MVR II (Complementos), p. 307. Nesse texto, ele começa dizendo que a vontade "constitui a natureza íntima, verdadeira e indestrutível do homem" e que em si mesma ela é "bewußtlos", ou seja, sem consciência. Portanto, os fenômenos conscientes estão imediatamente sob suspeita.

${ }^{4}$ Cf. SCHOPENHAUER, A. $N / N, 2013$.

5 SCHOPENHAUER, A. F/L, p. 471.

Afirmar e querer negar: os limites da negação da vontade na obra madura de Schopenhauer
} 
como tal, também é, como o restante do organismo, a própria vontade em sua objetidade, dessa vez como puro sujeito do conhecimento6. Isso produziria e canalizaria a vontade, diríamos a energia libidinal, para os objetos de contemplação, numa suspensão momentânea da relação com os alvos hodiernos da vontade, restando então, nesse momento, a possibilidade de uma concentração, de um foco, no objeto contemplado que proporciona a satisfação estética, que teria, para Schopenhauer, o efeito de suspender as demandas habituais do querer, por assim dizer parando por um momento a famosa roda de Íxion. É a hora do recreio da vontade. Nesse sentido, há uma passagem dos Ergänzungen, nesse capítulo mencionado acima, em que ele fala justamente da importância de uma atividade cerebral intensa, isto é, quão mais "desenvolvido e enérgico for o cérebro em geral", mais o objeto ficará distante do sujeito e, finalmente, produzir-se-á "esse estado de pura objetividade, que em si mesmo elimina a vontade da consciência, tornando todas as coisas diante de nós mais claras e distintas, de tal modo que ficamos muito mais cientes delas do que de nós mesmos"7. 0 estado, isto é, o efeito quietivo, não é de modo algum uma senha para que cheguemos à conclusão imediata de que a vontade em si é eliminada da consciência, mas sim aquela vontade relacionada à satisfação direta dos Triebe ligados diretamente ao todo do organismo. Então, considero problemático entender o efeito quietivo como algo além do que apenas um dos efeitos possíveis do belo, como, aliás, é também a opinião de Nietzsche a respeito, expresso na obra Genealogia da moral - uma polêmica:

Interpretemos agora o caso de Schopenhauer: evidentemente a visão do belo atuava nele como estímulo liberador da força principal de sua natureza (a força da reflexão e do olhar aprofundado); de modo que esta explodia e de imediato tomava conta da consciência. Com isso não se deve em absoluto excluir a possibilidade de que a peculiar doçura e plenitude própria do estado estético tenha sua origem precisamente no ingrediente "sensualidade" (assim como da mesma fonte vem o "idealismo" das moças núbeis) - de que, assim, a sensualidade não seja suspensa quando surge o estado estético, como acreditava Schopenhauer, mas apenas se transfigure e já não entre na consciência como estímulo sexual ${ }^{8}$.

Há, portanto, de acordo com essas observações de Nietzsche, uma impensada

\footnotetext{
${ }^{6}$ SCHOPENHAUER, A. WWV II/ MVR II (Complementos), p. 28.

7 Ibidem, p. 20.

8 NIETZSCHE, F. Genealogia da Moral: Uma Polêmica. Trad. de Paulo César de Souza, p. 101. Algumas páginas antes, Nietzsche alude ao que parece ser o principal interesse de Schopenhauer, o do torturado que quer se livrar de sua tortura, isto é, a veemência do impulso sexual.

Afirmar e querer negar: os limites da negação da vontade na obra madura de Schopenhauer
} 
fisiologia da estética, que antecipa em grande medida os escritos sobre a arte de Freud, ainda que não viesse completamente à luz em Schopenhauer ${ }^{9}$. Porém, como já foi adiantado neste escrito, não dependemos de Nietzsche ou de Freud para chegar a essas mesmas conclusões. 0 que nos diz Schopenhauer já bastaria para isso, ainda que em seu caso predomine a ambiguidade. Aliás, Nietzsche foi, de fato, um pouco maroto ao assumir a perspectiva fisiopsicológica apenas para si, aproveitando-se da perspectiva ressaltada por Schopenhauer na "Metafísica do belo" (o efeito quietivo na consciência) e se esquecendo do vigor afirmativo da vontade, do corpo e da sexualidade direta ou sublimada, no conjunto da obra tardia de Schopenhauer. Na verdade, trata-se mais de Schopenhauer em conflito consigo mesmo. 0 ideal ascético foi tratado por ele com certa parcialidade no contexto da arte para preservar a força maior, ou seja, o efeito direto que a obra de arte fazia sobre a sua própria subjetividade, escravizando, por assim dizer, os outros impulsos, as forças menores, devido justamente ao vigor intelectual do filósofo da vontade.

Podemos conceber que o Schopenhauer da "Metafísica do belo" expresse, de certa forma o mesmo que o barqueiro de sua própria metáfora dos Ergänzungen, e que as ondas possam ser comparadas à vontade, que tem como norte magnético o corpo e a sexualidade a ele inerente: Wille e Welle. Quando Schopenhauer afirma o efeito quietivo que a arte tem sobre ele mesmo como sendo algo universal, ou seja, afirma a sua própria vontade de negar o aspecto excitante do belo, já não se coloca em estado de isolamento em sua subjetividade e, de certa forma, participando da ilusão da individuação? Isto é, fazendo com que predomine a sua personalidade pulsional tomada como algo universal? Não se trataria novamente da imagem do homem que desconhece a identidade absoluta da vontade em todo fenômeno e ignora que sua existência individual é mera aparência, e que inclusive o impulso preponderante em sua personalidade faz parte de soluções de compromisso entre impulsos hierarquizados, proporcionando a eles uma forma determinada e enlaçando-os em torno de uma perspectiva fundamental ${ }^{10}$ ?

\footnotetext{
9 Sobre isso indico a leitura da introdução de Ernani Chaves ao livro traduzido por ele e lançado em 2015 sobre esses escritos freudianos. Pode ser profundamente revelador para o leitor sagaz de Schopenhauer, interessado em penetrar e tentar compreender esses meandros e circunvoluções no íntimo da obra. Poderíamos nos perguntar, com o perdão de usar um trocadilho, se a metafísica do belo, do ponto de vista da sensualidade, não será, de certo modo, uma pedalada filosófica de Schopenhauer, ao forçar a barra da dessensualização e, ainda por cima, com tanto ardor. Temos que manter o senso de humor ao tratar de coisas sérias.

10 BRUM, J. T. O pessimismo e suas vontades, p. 46. Em seu texto que contrapõe Schopenhauer e Nietzsche, o Afirmar e querer negar: os limites da negação da vontade na obra madura de Schopenhauer
} 
Assim como em meio ao mar enfurecido (tobenden Meere) que, ilimitado em todos os quadrantes, ergue e afunda montanhas d'água, um marinheiro (Schiffer) está sentado em seu pequeno barco (Kahn), confiando na frágil embarcação, da mesma maneira o homem individual permanece calmamente sentado, em meio a um mundo pleno de tormentos, apoiado e confiante no principium individuationis, ou modo como o indivíduo conhece as coisas como fenômeno ${ }^{11}$.

Se, por um momento, pensássemos no marinheiro como o próprio Schopenhauer, na frágil embarcação como a "Metafísica do belo" e no mar como a própria magnífica vontade sem-fundamento, veríamos também o puro sujeito do conhecimento apenas como um impulso (impulso que, como ele mesmo escreve, tem como foco e objeto a contemplação da ideia) reinante entre outros amalgamados em torno dele, quem sabe anestesiados em proveito do gozo comum, para proporcionar a ilusão de um belo que atenue a ponto de tornar quase invisível a expressão da sexualidade.

Apesar de todas as variações que os impulsos humanos permitem do ponto de vista da percepção de seus significados e alvos, cada um deles, como uma simples onda, ainda se baseia nesse funcionamento básico, espetacular e assustador, tal como uma força natural irrefreável, que não segue lei nenhuma propriamente, mas se apropria de todas as "leis" que lhe confiram a possibilidade de exercer efeitos com a mesma exuberância impetuosa da onda: até mesmo o efeito quietivo. Pois, também não seria assim o impulso do cérebro, o impulso ao conhecimento (de acordo com ou independente do princípio de razão)? A comparação alude simultaneamente ao aspecto cíclico do acúmulo e descarga de uma força acumulada, mesmo sendo um impulso ao conhecimento, exatamente como ocorre com as ondas que se sucedem. Cada onda é a primeira e a última, cada objeto se impõe apenas como alvo provisório, necessariamente ilusório, mas fundamental para permitir a descarga do afeto. Esse afeto, no caso uma alegria desinteressada, é admitido por Schopenhauer nos Ergänzungen. Bem como a força do intelecto e da vontade ao fundo dele.

Partindo dessa analogia entre onda e vontade, podemos avançar no conhecimento do objeto, não da perspectiva da consciência, mas da atividade cíclica dos impulsos, cuja referência básica para a consciência está dada nas relações de prazer desprazer e que

comentador lembra que a metáfora do marinheiro citada a seguir é mencionada em $O$ Nascimento da tragédia: KSA I, p. 28. Brum sugere também uma correlação entre o "princípio de individuação" de Schopenhauer e o "princípio estético apolíneo" de Nietzsche.

${ }^{11}$ SCHOPENHAUER, A. WWV I, § 63, p. 482.

Afirmar e querer negar: os limites da negação da vontade na obra madura de Schopenhauer 
não podem descansar, ainda que escondidos ao fundo de um supostamente puro sujeito do conhecimento, já que lançamos sobre isso a suspeita de que poderíamos estar falando especialmente acerca de um sintoma de Schopenhauer, uma idiossincrasia de sua própria natureza, uma peculiaridade de sua personalidade pulsional, como ele mesmo, partindo de pontos de vista contidos em sua obra, poderia, hipoteticamente, também sustentar contra si mesmo.

O que estou escrevendo aqui não é uma superinterpretação do conceito de belo schopenhaueriano, é apenas o ensaio de uma crítica de algo que considero um ponto mais fraco da argumentação do filósofo, independente do seu esforço de clareza e de sua honestidade no trato com a verdade filosófica. 0 que o denuncia, ao fundo de suas intenções conscientes, é justamente o ardor, a candente subjetividade com que defende posições muito parciais no que concerne ao efeito do belo. Algo que inclusive poderia ser objeto de autoanálise se ele estivesse um pouco menos comprometido com a noção de suspensão momentânea do querer, no andar de baixo, e com sua ética da negação da vontade (ela não é prescritiva, mas assume claramente uma posição pessimista e, nesse sentido, no andar de cima, condena a existência como algo que não deveria ter existido). Não estou dizendo que a vontade não possa ou não devesse ser negada, estou apenas questionando se essa negativa não guarda em seu bojo uma afirmativa da negação, como no caso admitido por Schopenhauer quando fala a respeito do suicídio e diz que ali há um derradeiro ato de afirmação da vontade.

Essa percepção da afirmação da vontade ao fundo da "supressão" parcial do querer, nos conduziria não a uma supressão propriamente dita, mas a uma subordinação das forças no âmbito do psiquismo, o que manteria os impulsos mais nitidamente sexuais subordinados e aparentemente suprimidos, apenas porque não mais adentram à consciência como impulsos sexuais. Nesse sentido, haveria uma sublimação no sentido psicanalítico, já que não haveria qualquer resistência ao impulso sublimado.

Isso em nada muda a percepção de que Schopenhauer eleva a arte a uma suprema importância, pois ela permite, através da contemplação e da atividade criativa, um estado superior de consciência, no qual os motivos habituais cessam momentaneamente de fazer efeito sobre a consciência, sendo substituídos pelo objeto sublimado, que proporciona uma alegria considerada desinteressada, pelo menos se tomarmos como referência os alvos habituais e práticos da vontade. 
No entanto, este é, de qualquer modo, um estado momentâneo, pois, somos sempre novamente obrigados a retornar ao duro chão da existência e encarar a realidade cotidiana, nossas necessidades e impulsos que visam satisfação direta. Novamente, após uma pausa para visitar o mundo das Ideias apresentadas nas obras de arte, retomamos nosso trabalho habitual e começamos a dar voltas na Roda de Íxion, sempre novamente picados pelas serpentes da efetividade que tem como seu principal ponto focal a sexualidade.

Como Freud comenta, anos mais tarde, não é possível uma sublimação completa do impulso e essa capacidade é variável de indivíduo para indivíduo, sendo absolutamente necessária a satisfação direta dos nossos impulsos, o que nos leva inevitavelmente ao sofrimento. Sem dúvida, há forte proximidade entre as abordagens de Schopenhauer e Freud do ponto de vista do reconhecimento da necessidade da positividade do sofrimento como consequência da busca de satisfação pulsional, especialmente no mundo civilizado, apesar do interesse metafísico de um e do pensamento clínico e metapsicológico do outro, o que resulta em objetivos, caminhos e conclusões diferentes em diversos níveis. Schopenhauer, por exemplo, nos alerta sobre isso em "Sobre o uso prático da razão e o estoicismo". Segundo o autor, o conforto, a alegria e o prazer pelos quais as pessoas procuram tornar a vida mais agradável, "podem produzir apenas novos e maiores flagelos do que aqueles que originariamente pertencem a ela". Consequentemente, "nosso sofrimento sempre surge a partir da desproporção entre os nossos desejos e o curso do mundo" ${ }^{12}$. Tudo funciona como se uma autodefesa de sua natureza contra o sofrimento comandasse e desse sentido ao impulso que, no caso específico do filósofo, parecia suprimir ou atenuar os outros.

\section{A força maior gasta a menor}

Dead to the world, to Heaven and to Hope! (Edgar Allan Poe, 1839)

Uma importante questão que surge para nós a partir das considerações de Schopenhauer em sua obra complementar é saber em que medida ocorre uma suspensão parcial do querer, e em que medida ocorre uma sutilização, uma sublimação, 
seja como Subliemirung, seja como Erhabenen ${ }^{13}$. Essas questões não são insignificantes. Elas determinam, por exemplo, o quanto as críticas de Nietzsche a Schopenhauer são válidas. E, após a experiência da psicanálise, desde os "Estudos sobre a histeria" até os dias atuais, temos também que interrogar ainda mais fortemente acerca dos impulsos que estão sendo satisfeitos em conjunto com o impulso intelectual, contemplativo, ainda que saibamos também que esse tipo de satisfação não se compare à afirmação direta do querer-viver que, talvez infelizmente, será em geral bem mais negada do que satisfeita, como adverte Schopenhauer (a força de magnitude menor de uma vontade enclausurada na individuação, que é contida por todas as outras simultâneas formas de individuação em processo de autoafirmação no vir-a-ser). No entanto, para quem pode usufruir esteticamente do mundo, pelo menos o efeito da arte parece ser próximo à ideia de um transporte para uma realidade alternativa, embora o que ocorra ao nível inconsciente permaneça sob júdice, exatamente como afirma... Schopenhauer! Perguntamo-nos nesse sentido por que justamente na estética esse inconsciente da sexualidade que permeia cada coisa não seja ressaltado, e respondemos com Nietzsche: devido a uma peculiaridade de Schopenhauer. É como se o Schopenhauer da "Metafísica do amor sexual" fosse uma espécie de William Wilson do Schopenhauer da "Metafísica do belo". Para os leitores de Edgar Poe, a imagem deverá parecer razoavelmente nítida. William Wilson é um duplo (supostamente um homônimo e um rival) do próprio narrador do conto de Poe que se queixa de ser perseguido em todos os lugares pelo outro e, ao final, descobrimos que são ambos a mesma pessoa ${ }^{14}$ (há inclusive um duelo no espelho).

O que diz Schopenhauer em outros lugares? Apenas a própria vontade pode negar a si mesma (e isso não é apenas um jogo de palavras). Não se trata de uma negativa racional, intelectual, ou algo assim. Trata-se, na verdade, de autodecepção e consequente retirada de investimento libidinal do objeto chamado Welt (mundo).

Mas, mesmo considerando que tal autodecepção ocorra e que não seja apenas um fenômeno, mas afete a própria relação da coisa em si consigo mesma no âmbito fenomênico, como nós poderíamos nos sentir seguros de reconhecer isso a partir de seus

13 Cf. FONSECA, E. R. Psiquismo e vida: Sobre a Noção de Trieb nas Obras de Freud, Schopenhauer e Nietzsche, p. 322. Podemos pensar também que se trata de uma afirmação atenuada, como nos sugere a colega pesquisadora Selma Bassoli em nossas discussões recentes sobre o assunto (em 2016, tanto em Curitiba, durante o IX Para saber mais Schopenhauer, quanto em Aracaju, durante o Encontro Nacional da ANPOF).

14 POE, E. A. William Wilson. In: The Complete Edgar Allan Poe Tales, p. 212.

Afirmar e querer negar: os limites da negação da vontade na obra madura de Schopenhauer 
efeitos exteriores, já que o querer é em si mesmo inconsciente e, portanto, um verdadeiro mestre do disfarce como nos adverte em diversos lugares Schopenhauer? Entendo que essa é uma questão que precisa ser enfrentada de alguma forma para que os raios da roda da bicicleta da vontade possam efetivamente convergir sempre para o centro, como ele mesmo ressalta, a partir do conceito de vontade. Se esta, no conjunto da natureza, afirma-se continuamente, no entanto, há algo que escapa ao nosso controle, foge às nossas deliberações conscientes e racionalizações tanto no confronto com as outras vontades igualmente decididas ao se afirmarem, como também frente ao desconhecido que representamos para nós mesmos. Esse é, portanto, o meu assunto: as modificações que partem imediatamente da vontade não entram necessariamente na consciência, podem inclusive aparecer de modo distorcido ou com uma aparência inteiramente diversa de suas reais motivações ou direção e, com isso, tanto se explica a diferença entre consciente e inconsciente, como se pode também, igualmente, questionar a possibilidade de estabelecer a negativa como algo mais do que uma afirmação disfarçada: "O traço fundamental da minha doutrina é a separação completa da vontade em relação à cognição"15. Para o filósofo não é natural que o nosso sistema nervoso se volte sobre si mesmo e se autoanalise, já que está voltado para fora e de dentro só quer o silêncio que é sempre suprimido por novos ruídos da experiência. 0 cérebro humano tem diante de si o exterior do corpo como "a sua luz mais fulgurante". No entanto, a razão, ao se voltar para o próprio íntimo do organismo material, percebe-o envolto em sombras, pois, segundo Schopenhauer, "nenhum princípio a priori iluminará a noite de nosso próprio íntimo (eigenen Innern)"16.

A cognição é mera função do organismo, algo secundário, a mera visibilidade ou fenômeno perceptível da vontade. Segundo a tese de Schopenhauer, se suprimirmos o organismo, o que resta é a coisa em si:

O que se manifesta na consciência de si mesmo (Selbstbewußsein), ou

15 SCHOPENHAUER, A. N/N, p. 66.

${ }^{16}$ SCHOPENHAUER, A. F/L, p. 540. Freud, em uma carta a Einstein, de 26 de março de 1929, reforça esse argumento do filósofo acerca da não naturalidade da abordagem mais profunda acerca do nosso próprio psiquismo: "Toda a nossa atenção está voltada para fora, de onde os perigos ameaçam e as satisfações acenam. De dentro, só queremos a paz. Assim, se alguém tenta voltar nossa consciência para dentro, [...] toda a nossa organização resiste - como, por exemplo, o esôfago e a uretra resistem a qualquer tentativa de reverter sua direção normal de passagem". Esse é o sentido íntimo da negativa. Obter senão a paz, ao menos um armistício frente ao clamor guerreiro e incondicional do querer autofágico da vontade, o prius do psiquismo. 
seja, subjetivamente (also subjektiv), como intelecto (der Intellect ist), na consciência das demais coisas (andere Ding), ou seja, objetivamente (also objektiv), aparece como cérebro (Gehirn): e o que na consciência de si mesmo, por conseguinte, subjetivamente, aparece como vontade, está representado na consciência das demais coisas, portanto objetivamente, como o organismo inteiro (gesamte Organismus) ${ }^{17}$.

Trata-se, portanto, de um elemento radical, a vontade, e a partir dela, as suas manifestações conscientes ou inconscientes, racionais ou vegetativas, decididas ou disfarçadas. Por isso o valor da negativa deve ser visto com cautela, na medida mesmo em que a própria vontade é cindida na efetividade e do conflito entre tendências pode surgir uma norma conciliatória, às vezes uma ilusão, uma fantasia, uma satisfação alucinatória qualquer, ou uma denegação. Muitos gostariam de ver na Metafísica do belo ou no ascetismo uma forma efetiva de libertação do querer, mas não se trataria talvez de um querer doente, um querer que quer não apenas negar, mas verdadeiramente repudiar a existência na individuação?

Há, no mínimo, um conflito íntimo entre as perspectivas de afirmação e negação no âmbito da filosofia do autor de "O Mundo como Vontade e Representação". Nesse sentido, segundo Cacciola, na filosofia de Schopenhauer "a afirmação do querer-viver contrapõe-se positiva e autonomamente à morte e à própria negação da Vontade". Segundo a autora, no texto "A Vontade e a Pulsão em Schopenhauer", "a atitude afirmativa guarda sua independência e especificidade para quem for capaz de aceitar a vida com todas suas vicissitudes"18. Inclusive, se é a vontade que nega a si mesma, não surgiria então, a partir desse ato de negar, uma afirmativa da própria negação? E o que significa essa atitude afirmativa frente ao mundo e também em relação ao próprio corpo, mesmo na sua negação, já que, para o filósofo, o corpo inteiro, inclusive o cérebro, é ele mesmo exposição da vontade, é objetidade da vontade e, como tal, acima de tudo quer de acordo com um caráter invariável (quer como é e é como quer)? Isto é, do mesmo modo como estamos ligados às miríades de redes causais existentes no mundo como representação, há também esse elemento imponderável que é a expressão do caráter individual ao longo da vida, o que engendraria a expectativa de inúmeros conflitos, tanto do ponto de vista do embate entre corpo e o mundo, e entre tendências e desejos divergentes de acordo com um mesmo caráter que apresenta em seu cerne a figura do 
conflito entre tendências a partir das quais ele existe e se manifesta no mundo concreto. Se olharmos o conjunto dos fenômenos, a negativa não pode ser uma negativa de todo querer e de todo fenômeno, mas sim apenas do querer e do fenômeno frente ao intelecto manifesto em condições específicas, posto que não temos o domínio sobre o que se manifesta como querer inconsciente tanto em cada caso particular, como também de modo geral. Senão, teríamos apenas uma filosofia de diversão e não poderíamos levar a sério o que ele nos diz sobre o significado do conceito de vontade no segundo livro dos “Complementos" traduzidos por mim e publicados em 2014, especialmente no capítulo XIX:

\begin{abstract}
A Vontade, como a coisa em si, constitui a natureza íntima, verdadeira e indestrutível do homem: Em si mesma ela é sem consciência [bewußtlos]. Assim, a consciência é condicionada pelo intelecto, e o intelecto é um mero acidente de nosso ser, pois é uma função do cérebro. 0 cérebro, juntamente com os nervos e com a medula espinhal ligada a ele, é um simples fruto, um produto. Na verdade, é um parasita do resto do organismo, na medida em que não interfere diretamente no funcionamento [Getriebe] íntimo do organismo, mas serve ao propósito de autopreservação, regulando as suas relações com o mundo externo. Por outro lado, o próprio organismo é a visibilidade, a objetidade ${ }^{19} \mathrm{da}$ vontade individual, sua imagem, tal como esta imagem apresenta a si mesma naquele mesmo cérebro (que no primeiro livro aprendemos a reconhecer como a condição do mundo objetivo em geral). Portanto, esta imagem é condicionada pelas formas de conhecimento do cérebro, ou seja, espaço, tempo e causalidade e, consequentemente, apresenta-se como algo extenso, sucessivamente atuante e material, em outras palavras, eficiente. As partes do corpo como um todo são diretamente sentidas e percebidas apenas no cérebro por meio dos sentidos. - Em consequência disso, pode-se dizer que o intelecto é o fenômeno secundário, enquanto o organismo é o principal, isto é, a manifestação fenomenal imediata da Vontade. - A Vontade é metafísica, o intelecto físico. - 0 intelecto, como seus objetos, é mero fenômeno, só a Vontade é a coisa em si. Então, em um sentido mais figurativo, e por isso mesmo somente a título de comparação, pode-se dizer que a vontade é a substância do homem, o intelecto o seu acidente. - A vontade é a matéria; o intelecto, a forma. A vontade é calor, o intelecto é luz ${ }^{20}$.
\end{abstract}

O modo como Schopenhauer analisa as três variações de um mesmo caráter individual, o egoísmo, a compaixão e a crueldade, permite a exposição do indivíduo na perspectiva de um conflito entre as tendências originais e cegas do caráter inteligível,

19 O neologismo "Objektität" citado aqui várias vezes é criado por Schopenhauer para expressar a sempre imediata exposição da Vontade e a vacuidade no que concerne à referência a um sujeito da consciência. Lembra as referências de Nietzsche, Grodeck e Freud a um "Es" [Isso] que se expõe imediatamente na ação humana, apesar da consciência e através dela. 
que expressa a vontade por assim dizer em estado puro, como prius da experiência, e a necessidade imposta pelo mundo e pelas vontades de outros inumeráveis indivíduos que também lutam pela afirmação da própria existência.

O contraste entre as tendências internas da vontade e a necessidade externa intuída se apresenta ao intelecto, o posterius ${ }^{21}$, como uma experiência que ao mesmo tempo em que visa a satisfação, não pode fazer dela mais do que um alvo momentâneo em meio à pluralidade e à diferença nas formas e características dos objetos naturais. Trata-se sempre de uma consciência imediata de um desejo e da alternância entre a sua satisfação ou insatisfação ${ }^{22}$. Por mais que um determinado indivíduo seguisse apenas desejos conforme o seu caráter inteligível, não deixaria de sofrer no plano íntimo pelo conflito entre desejos inconciliáveis e até mesmo contrários entre si $^{23}$. Além disso, caso ocorra uma conciliação provisória dos impulsos que dividem o sujeito internamente, o mundo exterior se encarregará de expor o organismo a toda sorte de contradições e necessidades, que novamente provocarão uma cisão entre o querer orgânico e a sua possibilidade prática de realização.

Assim como a vontade em geral não pode ser satisfeita, por não ter fundamento e não possuir alvo específico, também o caráter humano é expressão da mesma lei implacável. Por isso, o organismo está atado à sua vontade, ele é a sua própria vontade.

Essa exigência permanente do caráter individual em relação ao todo do organismo tem sua materialidade nas ações do corpo. Com isso, a Vontade que se efetiva no caráter empírico controla as ações musculares. Estas ações, por sua vez, têm sempre uma causa, que une a um só tempo o ímpeto cego da vontade e os motivos da experiência. O corpo é, portanto, vontade manifesta que, ao entrar em contato com motivos ocasionais (que obedecem à variedade condicionada da realidade), reage de uma maneira determinada e adequada ao caráter individual. A conduta revela, aos poucos, o caráter inteligível e suas possibilidades na experiência do mundo como representação.

A necessidade de um ato se revela só depois de tomada a decisão. Esta envolve, por um lado, a reflexão racional, que pode antecipar a possibilidade de um ato a partir de

\footnotetext{
${ }^{21}$ Ibidem, § 19, p. 310. Também: "das prius des Gehirns wie des ganzen Leibes" (Ibidem, § 20, p. 318). Utiliza "Prius" e "Kern unseres Wesens" em Ibidem, § 2, p. 378. Para Schopenhauer, a base da identidade pessoal é a Vontade. 22 SCHOPENHAUER, A. WWV II/ MVR II, p. 310.

23 SCHOPENHAUER, A. WWV I, p. 438.

Afirmar e querer negar: os limites da negação da vontade na obra madura de Schopenhauer
} 
um critério; e, por outro, o impulso, que visa um fim determinado, mas não necessário.

O intelecto apresenta uma função comunicacional e adaptativa. Nesse sentido, o pensamento que rege a história natural de Schopenhauer guarda certa similaridade com a noção de adaptação, no sentido de que a forma do organismo sempre diz respeito à sua funcionalidade (entendida aqui como a exposição biológica das tendências de caráter que ali se relacionam aos motivos que o excitam, o que está de acordo também com a fisiologia cerebral como órgão formador das representações, que é como uma projeção virtual do próprio querer metamorfoseado em sistema nervoso central, entendido como um parasita controlador de cada ínfima parte do organismo, mas tendo como mestra oculta a vontade que de fato ele também é, o que implica na possibilidade de transformação para melhor se adaptar, ainda que o organismo se esforce sempre para retornar ao leito de sua Ideia originária e imutável.

Uma função orgânica, uma singularidade anatômica, a interação entre os órgãos e também a própria subjetividade peculiar são formas de expressão desse caráter que define o indivíduo de um modo a priori, mas que guarda certa margem para a mudança na experiência, ainda que essa mudança diga respeito meramente ao modo de se relacionar com a efetividade, e não com uma transformação a posteriori do próprio caráter. 0 caráter teria então, de certa forma, o seu leito de Procusto, no qual tudo teria que se adaptar às suas medidas ou ser descartado como indesejável ${ }^{24}$.

Schopenhauer situa a atividade orgânica no âmbito do querer-viver, isto é, na relação entre a forma inata do organismo e seu modo de atividade específico que, por definição, independente da consciência, mas se vale dela para se expressar e se impor no mundo como representação. Enquanto o intelecto toma decisões, contempla as ações efetivas da vontade que ele mesmo é.

0 intelecto reflete sobre cada possibilidade de ação, mas quem dá a palavra final é a vontade na qual se enraíza o caráter inteligível. 0 intelecto é, de fato, passivo na hora da escolha, por ser secundário ao corpo como fenômeno primário da vontade individual que lhe é inacessível. No entanto, o intelecto concebe-se como conhecedor do próprio caráter através do histórico dos atos da vontade que em si mesma é inconsciente. 0

24 Procusto é uma personagem psicopática da mitologia grega. Ele possuía uma cama de ferro, que tinha seu exato tamanho, para a qual convidava todos os visitantes (em geral viajantes) a se deitarem. Se os hóspedes fossem demasiados altos, ele amputava o excesso de comprimento para ajustá-los à cama, e os que tinham pequena estatura eram esticados até atingirem o comprimento suficiente. Uma vítima nunca se ajustava exatamente ao tamanho da cama porque Procusto, secretamente, tinha duas camas de tamanhos diferentes. 
intelecto julga ter opções igualmente possíveis para entre elas fazer uma escolha, no que está enganado. Esta é, segundo Schopenhauer, a ilusão da liberdade empírica da vontade.

Se a dor e o conforto orgânicos representam para o psiquismo um totalmente imediato conhecimento íntimo dos sucessivos afetos (sukzessiven Regungen) da vontade $^{25}$, o senso íntimo do próprio corpo aparece através desses afetos e das ações musculares reais, no tempo e no espaço, sob a forma de sucessivos impulsos na direção de objetos exteriores orientam as ações. Toda ação do corpo é um ato da vontade, mas o intelecto tem a ilusão de ser livre para escolher dentre os motivos, quando na verdade só os apresenta a ela, a quem cabe a decisão final, caracterizada pela afirmação dos afetos:

$\mathrm{Na}$ esfera do intelecto a decisão entra de modo totalmente empírico, como conclusão final do assunto; contudo, esta se produziu a partir da índole interior, do caráter inteligível, da vontade individual em conflito com motivos dados, e, por conseguinte, com perfeita necessidade. 0 intelecto nada pode fazer senão clarear a natureza dos motivos em todos os seus aspectos, porém sem ter condições de ele mesmo determinar a vontade, pois esta lhe é completamente inacessível, sim, até mesmo, como vimos, insondável 26 .

Como nós poderíamos (a partir do que foi dito acima) abordar a questão da liberdade em sua relação com o caráter?

No "Ensaio sobre a liberdade da Vontade", o caráter é a índole empiricamente conhecida, persistente e invariável, de uma vontade individual ${ }^{27}$. E, posto que esse caráter seja um fator daquela ação exatamente tão necessário como o motivo, explica-se assim o sentimento de que nossos atos surgem a partir de nós mesmos, aquele "eu quero" que acompanha todas as nossas ações e em virtude do qual cada um as tem que reconhecer como suas ações, pelas quais, portanto, sente-se moralmente responsável. Este é, de novo, aquele "eu quero, e quero sempre apenas o que eu quero" [Ich will, und will stets nur was ich will], encontrado antes na investigação da autoconciência, - e que induz o entendimento ingênuo [rohen] a afirmar teimosamente uma liberdade absoluta para agir ou deixar de agir, um liberum arbitrium indifferentiae. Porém, isso é apenas a consciência do segundo fator da ação, que por si mesmo seria totalmente incapaz de produzi-la e que, por outro lado, ao surgir o motivo, é do mesmo modo incapaz de evitá-la. Porém, apenas se pondo em ação

25 SCHOPENHAUER, A. WWV II/ MVR II, p. 370.

${ }^{26}$ SCHOPENHAUER, A. WWV I, p. 344.

27 Ibidem, F/L, p. 565.

Afirmar e querer negar: os limites da negação da vontade na obra madura de Schopenhauer 
dessa maneira manifesta sua própria condição à faculdade de conhecer que, dirigida essencialmente para fora e não para dentro, só pode chegar a conhecer a índole de sua própria vontade empiricamente, a partir das ações. Este conhecimento que se faz mais próximo e cada vez mais íntimo é o que se chama propriamente de conciencia moral que, justamente por isso, apenas depois da ação se faz ouvir diretamente; antes o faz, em suma, apenas indiretamente, na medida em que eventualmente, por meio da reflexão e recordando casos semelhantes nos quais já tenha se manifestado, considere-a na deliberação como algo que deverá igualmente se apresentar no futuro ${ }^{28}$.

Este é o lugar de recordar a exposição que ofereceu Kant sobre a relação entre caráter empírico e inteligível e, com ela, sobre a compatibilidade da liberdade com a necessidade, exposição que, segundo Schopenhauer, pertence ao que há de mais belo e profundamente pensado de tudo quanto Kant e a Humanidade já produziram. Unicamente a partir dessa exposição se pode discernir como a estrita necessidade de nossas ações coexiste com a liberdade (de que dá testemunho o sentimento de responsabilidade), em virtude do qual nos consideramos os autores de nossos atos e estes precisam ser moralmente imputados a nós. A relação exposta por Kant entre o caráter empírico e o inteligível se baseia plenamente naquilo que constitui o traço fundamental de toda a sua filosofia, na opinião de Schopenhauer, a saber, na distinção entre fenômeno e coisa em si. Do mesmo modo como nele a perfeita realidade empírica do mundo da experiência coexiste com sua idealidade transcendental, também coexiste a estrita necessidade empírica do agir com sua liberdade transcendental. Assim, segundo o autor, o caráter empírico, assim como a totalidade do homem, é, enquanto objeto (Gegenstand) da experiência, um mero fenômeno, ligado por isso às formas de todo fenômeno, o tempo, o espaço e a causalidade e sujeito às suas leis; no entanto, a condição e fundamento de todo esse fenômeno, independente daquelas formas, como coisa em si e, portanto, não submetida a nenhuma distinção temporal e assim persistente e imutável, é o caráter inteligível, isto é, a vontade como coisa em si à qual corresponde, como sua qualidade, a liberdade absoluta, quer dizer, a independência da lei de causalidade (como mera forma dos fenômenos) ${ }^{29}$. Porém, essa é uma liberdade transcendental, quer dizer, que não irrompe no fenômeno, mas que está presente apenas na medida em que fazemos abstração do fenômeno e todas as suas formas para aceder àquilo que, fora de todo tempo, deve-se pensar como a nossa essência íntima. Em virtude dessa

28 Ibidem.

29 Ibidem.

Afirmar e querer negar: os limites da negação da vontade na obra madura de Schopenhauer 
liberdade, todos os feitos do homem são a sua própria obra, por mais necessariamente que surjam do caráter empírico em seu encontro com os motivos; porque esse caráter empírico é, simplesmente, o fenômeno do inteligível em nossa faculdade de conhecer ligada ao tempo, ao espaço e à causalidade ${ }^{30}$. Ou seja, de acordo com Schopenhauer, no mesmo trecho, tratase do modo e da maneira pelos quais se apresenta o nosso ser em si como ele mesmo é perante essa faculdade de conhecimento. Por conseguinte, o filósofo sugere que a vontade é, certamente, livre, porém apenas em si mesma e fora do fenômeno: neste, por outro lado, apresenta-se já com um caráter determinado em relação ao qual todas as suas ações têm que se adequar e, portanto, quando aquele é determinado de modo mais preciso pela adição de motivos elas serão necessariamente de um jeito e não de qualquer outro.

Como é fácil de ver, este caminho nos conduz a não mais buscarmos a obra de nossa liberdade em nossas ações individuais, de acordo com o senso comum, mas sim na total existência e essência de alguém ${ }^{31}$. Segundo Schopenhauer, existência e essência precisam ser pensadas como sua ação livre que, apenas por intermédio da faculdade de conhecer vinculada ao tempo, ao espaço e à causalidade, apresenta-se em uma pluralidade e diversidade de ações; ações que, no entanto, precisamente devido à unidade originária (ursprünglichen Einheit) do que nelas se apresenta, precisam realizar todas exatamente o mesmo caráter e que, portanto, aparecem como estritamente necessárias em função daqueles motivos pelos quais são suscitadas e determinadas no caso individual. Por conseguinte, segundo ele, o "Operari sequitur esse" é seguro, não admite exceção para o mundo da experiência. Nesse sentido, todas as coisas atuam de acordo com a sua natureza e todo homem atua de acordo com o que é; e a ação necessária conforme a natureza é determinada no caso individual unicamente pelos motivos. Entende-se, portanto, a partir disso, que, a liberdade, de acordo com o autor, não pode se encontrar no operari, mas sim precisa se enraizar no esse. É um erro fundamental, uma inversão completa de valores, atribuir a necessidade ao esse e a liberdade ao operari32. Pelo contrário, escreve Schopenhauer em seguida, a liberdade se encontra apenas no esse; mas, a partir dele e dos motivos, resulta necessariamente o operari: e no que fazemos conhecemos $o$ que somos [an dem was wir thun, erkennen wir was wir sind] ${ }^{33}$. Nisto, e não no suposto libero arbítrio indifferentiae, baseia-se a consciência da responsabilidade e a tendência moral

\footnotetext{
30 Idem, p. 566.

31 Idem, p. 567.

32 Ibidem.

33 Ibidem

Afirmar e querer negar: os limites da negação da vontade na obra madura de Schopenhauer
} 
que existe na vida. Tudo depende do que alguém é; o que quer que alguém faça, resultará disso por si mesmo, como um corolário necessário. A inegável consciência da arbitrariedade e originariedade (Ursprünglichkeit) que acompanha nossas ações apesar da sua dependência dos motivos, e em virtude da qual elas são nossas ações, não nos engana: porém, seu verdadeiro conteúdo se estende para além das ações e se inicia mais acima, por estarem aí compreendidas nossa existência e essência mesmas, das quais (por ocasião dos motivos) provêm necessariamente todas as ações ${ }^{34}$.

Em "Sobre a Liberdade da Vontade", o homem faz sempre o que quer e o faz necessariamente. Isso se deve a que ele é já o que quer: pois daquilo que ele é se segue necessariamente tudo o que ele faz a cada vez. Para o filósofo da vontade, caso se considere o obrar humano desde um ponto de vista objetivo, isto é, desde fora, então se percebe que ele tem que estar submetido, como o atuar de todo ser natural, à lei de causalidade em todo seu rigor. Mas, segundo ele, de um ponto de vista sujetivo (subjetivo), cada um sente que faz sempre só o que quer. Mas isso apenas significa que seu atuar é a pura exteriorização de seu próprio ser, como acontece não apenas com a Humanidade, mas com todo ser vivo.

Deste modo, a liberdade não é suprimida por Schopenhauer, mas somente deslocada desde o domínio das ações individuais, onde se demostrou que não podemos encontrá-la, até uma região mais elevada, mas não tão facilmente acessível para nosso conhecimento. Nesse sentido, ela é transcendental.

Nesse sentido, supondo então que a afirmação de si mesma é o próprio de toda vontade, pode ser que isso torne problemática a possibilidade de sua negação e talvez coloque, de certa forma, essa possibilidade sob suspeição; as afirmações de Schopenhauer de que seria possível que a vontade primeiro se afirmasse e depois se negasse, seja em sua hora de recreio, na contemplação do belo, seja na sua concepção de negação ascética presente no Livro 4 de "O mundo como Vontade e Representação" podem estar, portanto, sob suspeita de ser alguma outra coisa? 0 que justificaria essa possibilidade da supressão parcial ou completa do querer, se, com a mesma veemência e ardor com que o autor afirma a possibilidade da negação, afirma também a sutiliza e os ardis característicos da vontade nas mínimas coisas, no seu agir sorrateiro, forçando a consciência a concluir apenas o que ela já quer. Isso se dá porque o próprio conhecimento é uma forma de atividade da vontade. 
No capítulo dos Ergänzungen, intitulado "Sobre a objetivação da Vontade no organismo Animal", Schopenhauer escreve que é a "vontade de conhecer" que se objetiva no cérebro e em suas funções e que esse cérebro é uma parte do corpo e, como tal, também pertence à objetivação da vontade. Em outras palavras, o Erkennenwollen, o querer conhecer da vontade, é uma tendência para o mundo externo objetivada no cérebro 35 .

Nesse sentido, de acordo com o próprio Schopenhauer, atribuir valor excessivo ao conhecimento consciente é reflexo de uma necessidade de se iludir mediante os critérios inconscientes da vontade. Assim, é como se ao desejo fosse necessário simultaneamente crer na verdade, mas logo lhe bastasse apenas a simples ilusão, como está escrito em diversos pontos da sua obra, mas especialmente nos Ergänzungen sobre a vida da espécie e sobre a metafísica do amor sexual. A metáfora do intelecto como a babá que simultaneamente precisa satisfazer a vontade com determinados objetos e que muitas vezes a distrai com objetos ilusórios parece vir a calhar aqui. No quinto argumento do "Complemento" (1844) chamado "Sobre o Primado da Vontade na Autoconsciência", Schopenhauer escreve o seguinte:

\begin{abstract}
Platão (de acordo com Eliano, Variae Historiae, 13, 28) ${ }^{36}$ chamou apropriadamente a esperança de sonho de quem está acordado. Sua natureza está no fato de que a vontade obriga o seu servo, o intelecto, de qualquer modo, quando este é incapaz de produzir a coisa desejada, a retratar essa coisa para ela, e, geralmente, a assumir o papel de consolador, para pacificar a sua senhora e mestra, como uma babá faz com uma criancinha, com contos de fadas, de tal modo que estes lhe proporcionem uma aparência de verossimilhança. Aqui, o intelecto é obrigado a fazer violência à sua própria natureza, que visa à verdade, uma vez que é obrigado, ao contrário de suas próprias leis, a considerar como verdadeiras coisas que não são verdadeiras nem prováveis, e muitas vezes quase impossíveis, apenas com o intuito de pacificar, acalmar, e adormecer um pouco a vontade incansável e incontrolável. Vemos claramente aqui quem é a mestra e quem é o servo ${ }^{37}$.
\end{abstract}

Já que a vontade está sempre no comando, será que, como sugeriria um velho demônio, os livros 3 e 4 da obra magna não refletiriam uma vontade aprisionada, que

\footnotetext{
35 SCHOPENHAUER, A. WWV II / MVR II, p.385 e seguintes.

36 Claudius Aelianus (175 - 235 d. C.) escreveu esta miscelânea de anedotas sobre filósofos e esboços biográficos, listas, máximas concisas, descrições de maravilhas naturais, entre outras coisas, em um total de 14 volumes.

37 SCHOPENHAUER, A. WWV II/ MVR II, p. 328.

Afirmar e querer negar: os limites da negação da vontade na obra madura de Schopenhauer
} 
nega a si mesma não como uma libertação, mas sim pelo efeito de uma divisão interna de seus impulsos que ora se afirmam ora se negam (afirmam a autonegação), mas sempre de algum modo se afirmando? Pulsão de morte, autodiscórdia, vontade de destruição direta. Tais questões não podem ser desprezadas pelos leitores de Schopenhauer, especialmente após o advento da filosofia de Nietzsche e da Psicanálise, já que ambas descobriram, porventura, na sexualidade, o ponto fraco da filosofia do autor de "Sobre a Liberdade da Vontade".

\section{Resignação ou superação das condições anteriores da existência}

Se a exigência permanente do caráter individual em relação ao todo do organismo tem sua materialidade nas ações do corpo, não poderíamos imaginar, por exemplo, com o Nietzsche da "Genealogia da moral", que o suposto efeito quietiv do belo não seria ele mesmo resultante de uma especialização tóxica do querer que não impediria que ocorresse também, em outros casos, o efeito oposto, por exemplo, uma sutil e orgiástica exaltação do belo, como uma verdadeira arquitetura de anseios desmedidos se expressando através da obra como em outro caso retratado pelo mesmo Edgar Poe em sua obra "The Oval Portrait" ("O Retrato Ovalado") 38? No conto em questão o pintor apaixonado por sua musa resolve retratá-la para imortalizar sua beleza e a acaba matando por inanição e fadiga, em meio a um surto maníaco, no qual ele pinta incessantemente até ficar satisfeito, transferindo toda a beleza da moça para o retrato, por assim dizer imortalizando a amada que, finalmente, dá seu último suspiro simultaneamente à última pincelada do artista. Nesse sentido, a vida é transferida da jovem amada para a pintura, ao ponto do pintor exclamar, enquanto a jovem morria, admirando sua obra acabada: "This is indeed the Life itself!" [esta é, de fato, a própria vida] No retrato meramente pintado, de fato, estava a vida "em si mesma". Quando ele olha para o lado, no entanto, lá estava a sua amada já morta.

A estratégia que Schopenhauer usaria para comentar a obra é conhecida e podemos usar os seus critérios por ele. Por exemplo, poderíamos pensar que a compreensão do sentido íntimo dessa narrativa, o seu sentido trágico, ainda que numa cena cotidiana, nos conduziria ao estado de renúncia, à negação da vontade de viver. Ou seja, o que se exibe na cena de Poe é algo que seria melhor que não existisse. 
Por outro lado, é preciso ter em mente que a representação em obras de arte de eventos trágicos não conduz ao belo, de acordo com Schopenhauer, mas corresponde, isso sim, ao sublime dinâmico. Para o autor, nosso prazer na tragédia (Trauerspiel) não pertence ao sentimento do belo (Gefühl des Schönen), mas ao do sublime (Gefühl des Erhabenen)39. Para Schopenhauer esse é até mesmo "o mais alto grau deste sentimento" 40 . Segundo ele escreve, a visão do sublime na natureza permite então que nos desviemos da vontade e do egoísmo a ela ligado, a fim de nos comportarmos de uma maneira mais puramente intuitiva, o que, na linguagem dele, significa ou supressão parcial do querer ou ao menos, como quer Nietzsche, uma atenuação da percepção do querer. Na linguagem de Schopenhauer, a catástrofe trágica nos desvia da Vontade de viver [Willen zum Leben]. Assim, na tragédia, o lado terrível da vida nos é apresentado: “o choro e a lamentação da humanidade, o domínio do acaso e do erro, a queda dos justos, o triunfo dos maus"41. E então aquele aspecto do mundo é trazido diante de nossos olhos, “e ele se opõe diretamente à nossa vontade. Nessa visão nos sentimos convidados a evitar a nossa Vontade de viver e nunca mais querer [wollen] e amar [lieben]"42. E é nessa mesma página que há uma tremenda antecipação da pulsão de morte freudiana: "Mas, é assim que nos tornamos ainda mais conscientes de que ainda resta em nós algo diferente e que não proporciona um conhecimento positivo, mas apenas um negativo, como aquilo que não quer a vida" (idem). Portanto, cada tragédia exige uma existência de um tipo totalmente diferente, um mundo diferente, o conhecimento que só pode ser dado a nós indiretamente. No momento da catástrofe trágica, segundo ele, ficamos convencidos mais claramente de que a vida é um pesadelo do qual temos que acordar.

Nesta medida, o efeito da tragédia é análogo ao do sublime dinâmico (dynamisch Erhabenen), uma vez que, como este, nos eleva acima da vontade e do seu interesse, e nos coloca em um humor em que encontramos prazer, à vista do que diretamente se opõe à vontade. 0 que dá ao trágico de tudo, o que a forma em que aparece, a tendência característica para o sublime, é o início do conhecimento que o mundo e a vida não pode nos proporcionar nenhuma satisfação verdadeira, e não é válido, portanto, o nosso apego a eles. É nisto que o espírito trágico consiste e por isso nos conduz à resignação [Resignation $]^{43}$.

\footnotetext{
${ }^{39}$ SCHOPENHAUER, A. WWV II/ MVR II, p. 109.

40 Ibidem.

41 Ibidem.

42 Ibidem.

43 Idem, p. 110.
}

Afirmar e querer negar: os limites da negação da vontade na obra madura de Schopenhauer 


\section{O silêncio da vontade}

Há uma discussão posterior proposta por Nietzsche, na qual o autor da Genealogia da Moral questiona exatamente este ponto de vista de Schopenhauer. Para este último, segundo Cacciola ${ }^{44}$, o conhecimento é a única possibilidade de libertação do jugo da vontade, a única fonte da vida estética e da vida ética, que significam, respectivamente, contemplação e resignação. É nesse sentido que o filósofo sugere que a resignação é a essência do trágico. Assim, do mesmo modo que a sexualidade constitui o verdadeiro foco da vontade humana, enquanto esta se afirma, assim também a resignação ou supressão da vontade indicam o ponto de vista ético em que a Vontade sublimada nega a si mesma. Mas, por que a Vontade haveria de negar a si mesma, se Schopenhauer se esforça para indicar, simultaneamente, que o homem é impulso sexual concreto? Para Nietzsche, de um ponto de vista psicológico, haveria nisso uma decisão arbitrária que somente motivos íntimos ligados à questão da sexualidade poderiam explicar. A visão dionisíaca do mundo, ligada ao primeiro Nietzsche, que afirma a vida, opõe-se à negação da vontade, e especialmente ao pensamento schopenhaueriano de que a tragédia conduz à resignação (Resignation): “Quão diversamente falava Dionísio comigo! Quão longe de mim se achava justamente então todo esse resignacionismo! Em alemão, Nietzsche usa o termo "Resignationismus"45. Segundo ele, o resignacionismo não corresponde à psicologia do trágico: "A tragédia precisamente é a prova de que os gregos não foram pessimistas: Schopenhauer enganou-se aqui (vergriff sich hier), como se enganou em tudo"46. Para Nietzsche, ao contrário do que escreve Schopenhauer, a bela aparência tem a clara função de permitir a experiência do terrível e a sua assimilação universal, levando a vida adiante, isto é, afirmando o querer-viver e a destruição, estabelecidos como pressupostos da criação: "Minha filosofia é um platonismo invertido." Para Nietzsche, "quanto mais distante se está do ente verdadeiro, tanto mais pura, bela, e melhor, é a vida". 0 alvo é a "vida na aparência"47.

O movimento de báscula do conceito de sublimação do terreno estético para o

\footnotetext{
${ }^{44}$ CACCIOLA, M. L. Schopenhauer e a questão do dogmatismo, p. 112.

${ }^{45}$ NIETZSCHE, F. KSA I, p. 19.

46 NIETZSCHE, F. KSA VI, p. 309.

${ }^{47}$ NIETZSCHE, F. KSA 7, 7[156], p. 199.

Afirmar e querer negar: os limites da negação da vontade na obra madura de Schopenhauer
} 
moral põe em relevo o debate com Schopenhauer, e evidencia tanto a questão do perspectivismo das interpretações e a necessidade de autossuperação, quanto a generalização do fenômeno estético como estrutura originária da relação de objeto. Aquilo que é o próprio da natureza do impulso, ou seja, os seus alvos e objetos variáveis, definem a sutilização e a sublimação como características originárias do próprio impulso e a metáfora como seu representante no campo da linguagem.

Mas, o próprio Schopenhauer não nos deixa acreditar demais na noção de supressão parcial da vontade, quando, em seu texto sobre o Genie fala o seguinte: "A apreensão das Ideias está condicionada pelo fato de que o conhecedor é o puro sujeito do conhecimento e que a vontade desaparece completamente da consciência" ${ }^{48}$. Ressaltese que a vontade desaparece completamente da consciência, e não que ela desaparece efetivamente. Sabemos que muitas afecções ligadas a representações permanecem ativas no inconsciente quando estão fora da consciência e, com isso, nesse sentido, ser inconsciente é apenas uma qualidade do psíquico.

A vontade é a raiz do intelecto e se opõe a todas as atividades deste que sejam direcionadas para qualquer coisa alheia aos seus próprios objetivos. Portanto, o intelecto é capaz de uma ter uma apreensão puramente objetiva e profunda do mundo externo somente quando se destaca, por um tempo, seja como for, dessa sua raiz. Isso, quando bem compreendido, parece resultar num funcionamento consciente que não abarca os estados inconscientes da vontade.

No capítulo imediatamente anterior, chamado "Sobre o puro sujeito do conhecimento", Schopenhauer nos diz que "a vontade com os seus interesses abandona a consciência e o intelecto segue livremente as suas próprias leis" e como puro sujeito contempla o mundo objetivo, reparem, "ainda que a partir de seus próprios impulsos (Triebe) esteja no mais alto estado de tensão e atividade". Ou seja, o cérebro é parte do corpo e o filósofo concebe na atividade própria ao impulso cerebral, uma forma de expressão muito peculiar da própria vontade. 0 intelecto é instigado pelo não querer e assim a forma inerente às coisas se destaca em seu "verdadeiro e pleno significado" 49.0 fato de existir um afeto ligado ao não querer que nos instiga é o dado primordial que nos mostra que a consciência é aqui, como em Freud, apenas uma qualidade do psíquico e

48 SCHOPENHAUER, A. WWV II/ MVR II, p. 36.

${ }^{49}$ SCHOPENHAUER, A. WWV II/ MVR II, p. 28.

Afirmar e querer negar: os limites da negação da vontade na obra madura de Schopenhauer 
não a sua característica fundamental, na medida em que ela é sempre direcionada por um querer ou um não querer, por um afirmar ou negar que são inflexões da própria vontade se manifestando nos filamentos do real, mesmo que fora do acesso da consciência que conhece.

\section{Referências bibliográficas}

CACCIOLA, M. L. Schopenhauer e a questão do dogmatismo. São Paulo: EdUSP, 1994.

. A vontade e a pulsão em Schopenhauer. In: MOURA, A. H. de. As pulsões. São Paulo: Editora Escuta, 1995.

FONSECA, E. R. Psiquismo e vida: Sobre a Noção de Trieb nas Obras de Freud, Schopenhauer e Nietzsche. Primeira reimpressão. Curitiba: Editora UFPR, 2016.

NIETZSCHE, F. Kritische Studienausgabe. Org. Giorgio Colli e Mazzino Montinari, 15 vols., Munique, DTV/ de Gruyter, 2ª ed., 1999.

Obras Incompletas. In: Os pensadores. Tradução de Rubens Rodrigues Torres Filho. São Paulo: Abril Cultural, 1978.

. O nascimento da tragédia - ou helenismo e pessimismo. Tradução de J. Guinsburg. São Paulo: Companhia das Letras, 1992.

. A Gaia Ciência. Trad. Paulo César de Souza. São Paulo: Companhia das Letras, 2001.

. Genealogia da Moral - uma polêmica. Trad. Paulo César de Souza. São Paulo: Companhia das Letras, 1998.

. Ecce Homo - Como alguém se torna o que é. Trad. Paulo César de Souza. São Paulo: Companhia das Letras, 2005.

POE, E. A. The complete Edgar Allan Poe Tales. New York: Avenel Books, 1981.

SCHOPENHAUER, A. Sämtliche Werke, ed. Wolfgang Frhr. von Löhneysen, Frankfurt, 1986, 5 vols. . Die Beiden Grundprobleme der Ethik, I: Über die Freiheit des Willens, Os Dois Problemas Fundamentais da Ética, I: Sobre a Liberdade da Vontade -1841. Trad. Eduardo Ribeiro da Fonseca, em fase de publicação pela Editora UFPR, 2017.

. Die Welt als Wille und Vorstellung, Ergänzungen [O mundo como vontade e representação: Complementos] - 1844 (2 a. ed.); 1859 (3a. ed). Trad. Eduardo Ribeiro da Fonseca, em dois volumes. Curitiba: Editora UFPR, 2014.

Über den Willen in der Natur [Sobre a vontade na natureza] - 1836. Trad. Gabriel

Valladão Silva. Porto Alegre: L\&PM, 2013. 